\title{
Fertirrigação com água salina e seus efeitos na produção do pepino en- xertado cultivado em ambiente protegido
}

\author{
Flávio F. Blanco; Marcos Vinícius Folegatti; Maria Cristina S. Nogueira \\ USP, Av. Pádua Dias, 11, C. Postal 09, 13.418-900 Piracicaba-SP. E-mail: ffblanco@carpa.ciagri.usp.br
}

\begin{abstract}
RESUMO
A aplicação de fertilizantes via água de irrigação nos cultivos protegidos, bem como a utilização de água subterrânea com alta concentração salina, tem resultado no aumento da salinidade do solo, ocasionando perdas de produtividade. Este trabalho teve o objetivo de avaliar a produção da cultura do pepino enxertado, cultivado em ambiente protegido, quando irrigado com águas de diferentes condutividades elétricas $\left(\mathrm{S} 1=1,54 ; \mathrm{S} 2=3,10\right.$ e S3 $\left.=5,20 \mathrm{dS} . \mathrm{m}^{-1}\right)$ e duas lâminas de irrigação associadas às suas freqüências de aplicação ( $\mathrm{L} 0=1,00 . \mathrm{ETc} ; \mathrm{L} 1 \mathrm{~F} 1=1,25 . \mathrm{ETc}$ em todas as irrigações e $\mathrm{L} 1 \mathrm{~F} 2=1,25$.ETc quando a lâmina de água de irrigação acumulada em L0 atingia $100 \mathrm{~mm}$ ), sendo ETc a evapotranspiração da cultura. O ensaio foi conduzido em blocos casualizados com três repetições e os fatores foram arranjados no esquema fatorial $3 \times 3$. O número de frutos comerciais por planta reduziu linearmente com o aumento da salinidade, enquanto a produção total e comercial, bem como o número total de frutos por planta e a produção de matéria seca de frutos não foram afetados significativamente pela salinidade, embora todas as características tenham apresentado tendência de redução com o aumento da salinidade da água de irrigação. As diferentes lâminas de irrigação não foram suficientes para reduzir os efeitos do estresse salino, independente das suas freqüências de aplicação.
\end{abstract}

\begin{abstract}
Fertigation with saline water and its effects on yield of greenhouse grafted cucumber

Fertiliser application through irrigation water in greenhouse crops, as well as the use of groundwater with high salt concentration, has been the cause of increasing soil salinity, leading to an expressive yield reduction. The yield of grafted cucumber in greenhouse when irrigated with waters of different electrical conductivity was evaluated $\left(\mathrm{S} 1=1.54 ; \mathrm{S} 2=3.10\right.$ and $\left.\mathrm{S} 3=5.20 \mathrm{dS} . \mathrm{m}^{-1}\right)$ and two irrigation water depths associated to their application frequencies $(\mathrm{L} 0=1.00$.ETc; $\mathrm{L} 1 \mathrm{~F} 1=1.25 . \mathrm{ETc}$ in all irrigation and $\mathrm{L} 1 \mathrm{~F} 2=1.25 . \mathrm{ETc}$ when the irrigation water depth of L0 reached $100 \mathrm{~mm}$ ), where ETc is the crop evapotranspiration. The trial was conducted in completely randomised blocks in a $3 \times 3$ factorial scheme. The number of marketable fruits per plant decreased linearly with salinity increase, while total and marketable yield, as well as the total fruit number per plant and fruit dry matter were not affected by salinity, even though all of them showed a reduction tendency with the increase in the salinity of the water. The different irrigation water depths were not sufficient enough to alleviate salt stress, independently of their application frequency.
\end{abstract}

Keywords: Cucumis sativus L., greenhouse, salinity.

Palavras-chave: Cucumis sativus L., ambiente protegido, salinidade.

(Recebido para publicação em 29 de setembro de 2000 e aceito em 27 de março de 2002)

$\mathrm{G}$ rande parte da tecnologia utilizada na irrigação em ambiente protegido é importada, principalmente, de países como Israel e Estados Unidos, que cultivam hortaliças neste sistema há mais de 30 anos. Uma destas tecnologias é a fertirrigação, que permite um maior parcelamento dos fertilizantes e, conseqüentemente, o aumento da eficiência de utilização dos fertilizantes pelas plantas.

Porém, a adição de fertilizantes na água de irrigação a torna salina, sendo a salinidade da água proporcional à quantidade de sais dissolvidos. Em estudo realizado por Oliveira \& Salati (1981), foi verificado que $38 ; 28$ e $6 \%$ dos poços da região de Piracicaba possuíam água com salinidade acima de 0,$75 ; 2,25$ e 4,00 dS.m ${ }^{-1}$, respectivamente, sendo que as águas mais salinas apresentavam mais de $90 \%$ da composição equivalente dos cátions composta de sódio e cer- ca de $60 \%$ dos ânions era cloretos e $30 \%$, sulfatos. Estas águas apresentam risco potencial de salinização do solo. Ao se utilizar a fertirrigação, este risco tornase ainda maior, sendo necessária a adoção de um manejo da irrigação que possibilite a lixiviação do excesso de sais da zona radicular.

Normalmente, a salinidade em áreas irrigadas é conseqüência do uso de água de qualidade inadequada, associado ao manejo inadequado do sistema solo-água-planta (Medeiros \& Gheyi, 1994). Qualquer que seja a fonte, a água utilizada na irrigação sempre contém sais, embora a quantidade e a qualidade de sais presentes nela possam variar bastante.

Em ambiente protegido, o excesso de fertilização, o uso de água salina e a ausência de drenagem adequada são fatores que contribuem para o maior risco de salinização do solo. Segundo Van Hoorn \& Van Alphen (1994), a concentração de sais no solo cresce em função da lâmina de irrigação aplicada, até que a salinidade do solo atinja o equilíbrio dinâmico. Segundo Bernardo (1995), atualmente, a principal causa do aumento da salinização dos solos agrícolas tem sido as irrigações mau feitas. Em ambiente protegido, Blanco \& Folegatti (1999) reportam que mesmo quando se utiliza água de irrigação de boa qualidade e concentrações adequadas de fertilizantes, pode ocorrer o acúmulo de sais na região radicular se não forem adotadas medidas de controle.

Decréscimos bastante significativos na produtividade do pepino em ambiente protegido têm sido obtidos em diversos estudos. Sonneveld \& Voogt (1978) obtiveram um decréscimo na produção de pepino da ordem de $17 \%$ 
para o aumento de uma unidade de salinidade da água de irrigação. Porém, a água salina foi aplicada através de um sistema de irrigação por aspersão, sendo que este sistema, conforme demonstram Gornat et al. (1973), não é adequado para a irrigação do pepino quando a água contém altos teores de sais, provocando alterações fisiológicas nas plantas. Chartzoulakis (1990) verificou que o número de frutos por planta e o peso médio dos frutos reduziram significativamente quando a salinidade da água de irrigação foi superior a 1,3 dS.m ${ }^{-1}$, sendo de $15,9 \%$ a redução de produtividade para cada unidade de salinidade acrescida na água de irrigação. De acordo com Maas \& Hoffman (1977), a produção do pepino começa a ser afetada quando a salinidade do solo ultrapassa o valor limite de 2,5 dS.m ${ }^{-1}$, ocorrendo um decréscimo de $13 \%$ na produção para cada unidade de salinidade acima deste valor, sendo considerada uma cultura moderadamente sensível à salinidade.

Este trabalho teve o objetivo de avaliar a produção do pepino enxertado, em ambiente protegido, quando irrigado com águas de diferentes salinidades e diferentes lâminas de irrigação e freqüência de aplicação da lixiviação.

\section{MATERIAL E MÉTODOS}

O experimento foi conduzido na área experimental da ESALQ, no município de Piracicaba (SP), em Terra Roxa Estruturada, série "Luiz de Queiroz", cujo material de origem são rochas básicas, de textura argilosa (46\% de argila). A análise de fertilidade do solo apresentou teores altos para todos os nutrientes, dispensando a adubação de fundação.

A cultura utilizada foi o pepino japonês (Cucumis sativus L.), cultivar Hokushin, enxertado sobre Cucurbita spp., híbrido Excite-Ikki. A cultivar Hokushin apresenta crescimento indeterminado, frutos de coloração verde escura brilhante, aproximadamente $20 \mathrm{~cm}$ de comprimento e diâmetro médio de 2,5-3,0 cm e a colheita inicia-se aos 40-50 dias após o transplantio (DAT), podendo prolongar-se por até 120 dias (Cañizares, 1998). As mudas foram adquiridas de um produtor da re- gião de Piracicaba, sendo a enxertia realizada pelo método da encostia conforme Papadopoulos (1994). A cultura foi conduzida com uma haste por planta em fitilhos verticais, retirando-se todas as folhas e brotações até o quinto internódio a partir da base da planta. Do sexto internódio em diante permitiu-se o desenvolvimento das brotações laterais, as quais tiveram os ponteiros cortados após o surgimento do terceiro internódio. Não foi realizada a decepa apical e nem o desbaste de frutos após o sexto nó.

O delineamento experimental foi de blocos casualizados completos, em esquema fatorial $3 \times 3$, com três repetições. Os tratamentos consistiram da combinação de 3 níveis de salinidade da água de irrigação $(\mathrm{S} 1=1,54 ; \mathrm{S} 2=3,10 \mathrm{e}$ $\mathrm{S} 3=5,20 \mathrm{dS} . \mathrm{m}^{-1}$ ) e 3 lâminas de irrigação associadas às suas freqüências de aplicação

$(\mathrm{L} 0=1,00 . \mathrm{ETc}$; $\mathrm{L} 1 \mathrm{~F} 1=1,25$.ETc em todas as irrigações e $\mathrm{L} 1 \mathrm{~F} 2=1,25$.ETc quando a lâmina de água de irrigação acumulada em L0 atingia $100 \mathrm{~mm}$ ), sendo a ETc a evapotranspiração da cultura. Para o tratamento L1F2, as irrigações foram feitas de maneira idêntica ao tratamento L0 e sempre que a lâmina de irrigação acumulada no tempo alcançava 100 $\mathrm{mm}$, as parcelas submetidas ao tratamento L1F2 recebiam quantidade suficiente de água de modo que a quantidade total recebida desde o início do período experimental se igualasse à quantidade recebia pelo tratamento $\mathrm{L} 1 \mathrm{~F} 1$. Como a lâmina total aplicada durante o ciclo da cultura foi de $198 \mathrm{~mm}$ para o tratamento L0, foi realizada apenas uma aplicação de L1 acumulada nos tratamentos L1F2, sendo esta aos 75 DAT, quando a lâmina de irrigação acumulada em L0 alcançou 103 mm. Portanto, neste dia, foi aplicada uma lâmina adicional de irrigação de $25,75 \mathrm{~mm}$ nas parcelas L1F2.

O ambiente protegido foi construído numa área anteriormente utilizada em ensaios com milho e feijão, principalmente, irrigados por sulcos. Por ocasião da sua construção, aproximadamente nove meses antes do transplantio, foi realizada a correção do $\mathrm{pH}$ e adição de $10 \mathrm{~kg}$ de superfosfato simples e $3,85 \mathrm{~m}^{3}$ de composto orgânico na área. Antes do cultivo do pepino nenhuma cultura foi conduzida no interior do ambiente, o qual apresentava área total de $110 \mathrm{~m}^{2}$, pé direito de $2,8 \mathrm{~m}$, com sombrite nas laterais e nos fundos. As laterais possuíam cortinas que eram abertas pela manhã e fechadas no final da tarde e na ocorrência de chuvas para evitar que a água atingisse as parcelas experimentais. Foram dispostas nove parcelas na direção do comprimento e três na direção da largura do ambiente protegido, sendo que cada parcela apresentava as dimensões de 1,85 m de comprimento por $2 \mathrm{~m}$ de largura, totalizando 27 parcelas. Nesta área foi levantado um canteiro de $1,85 \mathrm{~m}$ de comprimento por 1 $\mathrm{m}$ de crista.

O transplantio foi realizado em 23/ 06/1999, em filas duplas, no espaçamento de $0,7 \mathrm{~m}$ entre linhas, 0,4 $\mathrm{m}$ entre as plantas úteis e 1,3 m entre as filas duplas. As parcelas experimentais foram compostas de 10 plantas na densidade de 2,5 plantas. $\mathrm{m}^{-2}$ e foram separadas transversal e lateralmente até 0,8 $m$ de profundidade por uma lâmina plástica de $0,15 \mathrm{~mm}$ de espessura para evitar o deslocamento lateral de água e de sais entre as parcelas.

O manejo da irrigação foi realizado com base nas leituras de um tanque de evaporação reduzido e de tensiômetros localizados a 0,15 e $0,30 \mathrm{~m}$ de profundidade, aproximadamente a $0,10 \mathrm{~m}$ de distância da planta e do gotejador. O tanque apresentava diâmetro de $0,60 \mathrm{~m} \mathrm{e}$ $0,25 \mathrm{~m}$ de altura e foi instalado no interior do ambiente protegido, entre dois canteiros, sobre um estrado de madeira de $0,15 \mathrm{~m}$ de altura. A partir da leitura da lâmina de água evaporada no tanque reduzido pôde-se estimar a evaporação do tanque "Classe A" para o interior do ambiente protegido apenas multiplicando-se a evaporação deste pela constante 0,88 , a qual foi determinada por Medeiros et al. (1997). Dessa forma, a lâmina de irrigação era calculada com base na evaporação do tanque "Classe A”, estimada a partir da evaporação do tanque reduzido, assumindo Kp igual a 1,0 (Martínez-Raya \& Castilla, 1989; Castilla et al., 1990), e o ajuste da lâmina era feito pela leitura do tensiômetro mais profundo nas parcelas S1L0. Quando, no dia após à irrigação, o tensiômetro indicava que a umidade a 0,30 m não havia atingido a capacidade de campo, 
o coeficiente de cultivo $(\mathrm{Kc})$ para a próxima irrigação era aumentado, resultando no aumento da lâmina de irrigação.

O sistema de irrigação utilizado foi o gotejamento, com emissores de vazão média de 4,0 L.h ${ }^{-1}$ e um emissor por planta, situado a $2 \mathrm{~cm}$ de distância do caule. Os adubos foram misturados manualmente à água de irrigação em caixas d'água de 500 litros de capacidade. Os adubos utilizados foram: sulfato de amônio, nitrato de cálcio, ácido fosfórico, nitrato de potássio, cloreto de potássio e sulfato de magnésio, sendo que todos os tratamentos receberam $1 / 4$ do $\mathrm{N}$ na forma de amônio e $3 / 4$ na forma de nitrato. Para as águas S2 e S3, além dos adubos, foram adicionados os sais cloreto de sódio, cloreto de cálcio e sulfato de magnésio, em proporções adequadas para cada nível de salinidade, de modo que a relação equivalente de $(\mathrm{Na}+\mathrm{K}): \mathrm{Ca}: \mathrm{Mg}$ fosse de 5:3:2. O parcelamento da adubação durante $o$ ciclo da cultura foi realizado conforme recomenda Papadopoulos (1994).

As colheitas foram iniciadas em 26/ 07/99, aos 33 DAT, sendo os frutos classificados em comerciais e não comerciais. Foram considerados frutos não comerciais apenas os frutos excessivamente tortos e mal formados. Quinzenalmente, foram realizadas determinações da porcentagem de matéria seca em três frutos comercias por parcela, tomados ao acaso, sendo esta utilizada no cálculo da produção total de matéria seca de frutos por hectare.

$\mathrm{Na}$ análise estatística das variáveis estudadas, o fator quantitativo 'níveis de salinidade da água de irrigação' foi avaliado através da análise de regressão, enquanto que o fator qualitativo 'lâminas de irrigação associadas às suas freqüências de aplicação' foi avaliado através do teste de Dunnett unilateral.

\section{RESULTADOS E DISCUSSÃO}

A produção comercial (PC) e total (PT) aumentou de forma praticamente constante até o $90^{\circ} \mathrm{DAT}$, quando então o ritmo de produção de frutos foi intensificado devido ao grande número de ramificações laterais, independente dos tratamentos aos quais as plantas foram submetidas.
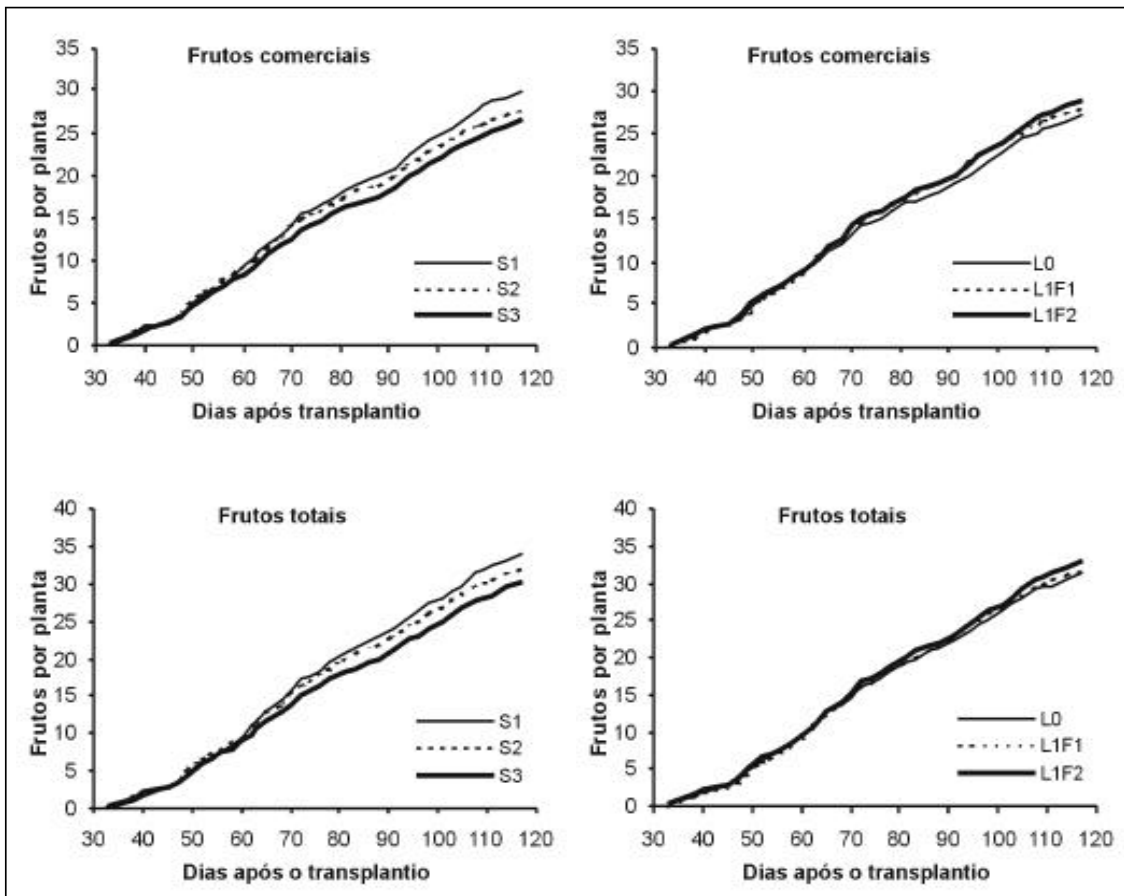

Figura 1. Número de frutos comercial e total por planta de pepino, para cada salinidade da água (A) e lâmina de irrigação (B), em função do número de dias após o transplantio. Piracicaba, ESALQ/USP, 1999.

As diferenças na produção acumulada aumentaram gradativamente até $\mathrm{o}$ final do ciclo, quando a PC para as salinidades $\mathrm{S} 2$ e $\mathrm{S} 3$ foram reduzidas de 6,72 e $10,33 \%$ em relação a S1 e a PT de 4,77 e $9,63 \%$, respectivamente. Para as diferentes lâminas de irrigação e frequiências de aplicação de L1, o aumento na PT foi de 2,38 e $9,43 \%$ para $\mathrm{L} 1 \mathrm{~F} 1$ e L1F2, respectivamente, em relação a L0. Para a PC, L1F1 superou L0 em $2,37 \%$, enquanto que L1F2 em 8,59\%.

Com relação aos componentes de produção (Figura 1), verifica-se a redução no número de frutos comercial (NFC) e total (NFT) por planta com o aumento da salinidade da água de irrigação. Para S2, o NFC foi 10,83\% inferior ao obtido com a água $\mathrm{S} 1 \mathrm{e}$, para S3, esta diferença foi de $11,43 \%$. O NFT para S2 e S3 foi, respectivamente, 5,09 e $7,05 \%$ inferior a $\mathrm{S} 1$ e as freqüências de aplicação de L1 resultaram em aumento no NFT e NFC, respectivamente, de 1,79 e $3,84 \%$ para $F 1$ e de 5,77 e $7,35 \%$ para $\mathrm{F} 2$, em relação a $\mathrm{L} 0$, provavelmente devido ao maior volume de água aplicado nestes tratamentos, o que contribuiu para elevar o potencial mátrico do solo, resultando no aumento do potencial total e, conseqüentemente, facilitando a absorção de água pelas plantas submetidas aos tratamentos mais salinos.

A PC e PT não foram afetadas significativamente pela salinidade da água (Figura 2), bem como pelas lâminas de irrigação associadas às suas freqüências de aplicação (Tabela 1), o que também ocorreu para o peso médio dos frutos (PMF) e NFT. O NFC reduziu linearmente com o aumento da salinidade da água, não sendo afetado significativamente pelas lâminas de irrigação associadas às suas frequiências de aplicação. Portanto, o principal efeito da irrigação salina no pepino "Hokushin", enxertado sobre Cucurbita spp híbrido Excite-Ikki, em ambiente protegido foi a redução do número de frutos comercial por planta, uma vez que o peso médio dos frutos não foi afetado pela salinidade, concordando com os dados obtidos por Jones et al. (1989). Estes autores verificaram que a produção relativa do pepino em ambiente protegido, irrigado com água de salinidade de $4,0 \mathrm{dS} \cdot \mathrm{m}^{-1}$, variou de 0,32 a 0,80 entre as diferentes cultivares utilizadas, em comparação com plantas irrigadas com água de boa qualidade $\left(1,6 \mathrm{dS} . \mathrm{m}^{-1}\right)$, indicando existir variabilidade genética 

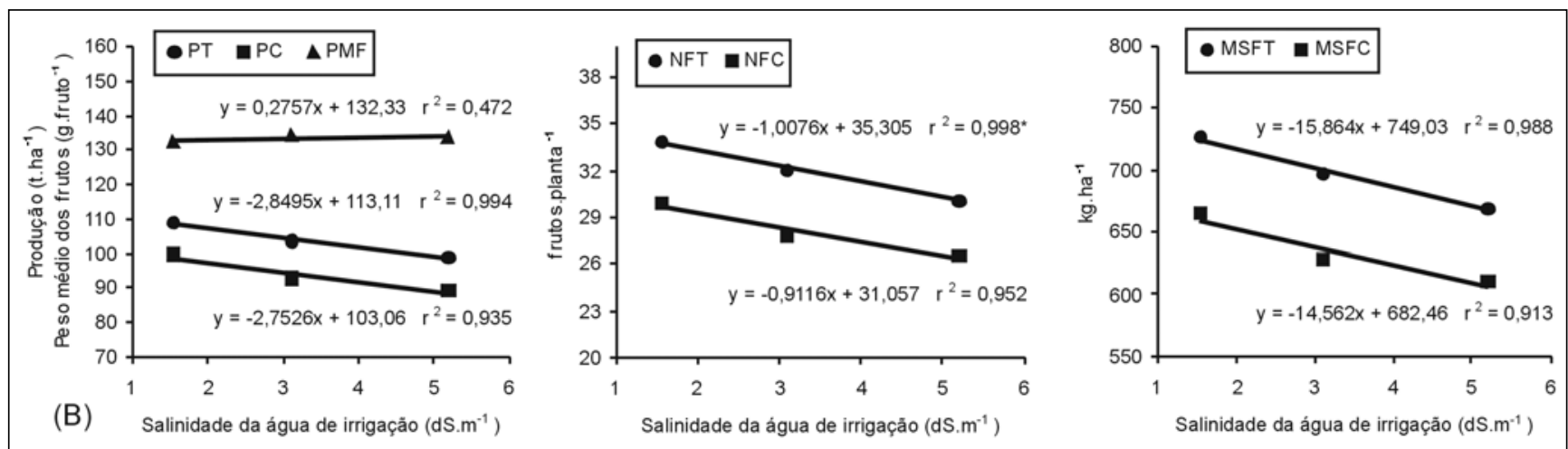

Figura 2. Resultados da análise de regressão dos níveis de salinidade da água de irrigação para: (A) Produção total (PT), comercial (PC) e peso médio dos frutos (PMF); (B) Número de frutos total (NFT) e comercial (NFC); (C) matéria seca de frutos total (MSFT) e comercial (MSFC). * Significativo ao nível de 0,05 de probabilidade pelo teste F. Piracicaba, ESALQ/USP, 1999.

Tabela 1. Produção total (PT) e comercial (PC), peso médio de frutos comerciais (PMF), número de frutos total (NFT) e comercial (NFC), matéria seca de frutos total (MSFT) e comercial (MSFC) de pepino, para as diferentes lâminas de irrigação associadas às suas freqüências de aplicação. Piracicaba, ESALQ/USP, 1999.

\begin{tabular}{|c|c|c|c|c|c|c|c|}
\hline \multirow{2}{*}{$\begin{array}{l}\text { Lâmina/Fre- } \\
\text { quência }\end{array}$} & PT & PC & \multirow{2}{*}{$\begin{array}{c}\text { PMF } \\
\text { (g.fruto }^{-1} \text { ) }\end{array}$} & NFT & NFC & MSFT & MSFC \\
\hline & \multicolumn{2}{|c|}{$\left(\right.$ t.ha $\left.^{-1}\right)$} & & \multicolumn{2}{|c|}{ (frutos.planta $^{-1}$ ) } & \multicolumn{2}{|c|}{$\left(\right.$ kg.ha $\left.^{-1}\right)$} \\
\hline$\overline{L O}$ & 100,8 & 90,5 & 133,3 & 31,2 & 27,1 & 678,3 & 611,3 \\
\hline L1F1 & $101,9^{\text {ns }}$ & $92,7^{\mathrm{ns}}$ & $132,0^{\text {ns }}$ & $31,8^{\text {ns }}$ & $28,1^{\text {ns }}$ & $684,4^{\text {ns }}$ & $625,5^{\text {ns }}$ \\
\hline L1F2 & $111,1^{\mathrm{ns}}$ & $99,0^{\text {ns }}$ & $134,4^{\mathrm{ns}}$ & $33,0^{\text {ns }}$ & $29,1^{\text {ns }}$ & $728,3^{\text {ns }}$ & $667,2^{\text {ns }}$ \\
\hline
\end{tabular}

ns Não significativo ao nível de 0,05 de probabilidade pelo teste de Dunnett unilateral, em relação a L0.

para tolerância à salinidade dentro das cultivares. A redução na produção foi devida à redução no número de frutos comerciais produzidos, sendo que a produção não comercial e o formato dos frutos não foram alterados.

Não houve diferenças significativas para a produção de matéria seca dos frutos comerciais (MSFC) e totais (MSFT) de pepino, embora tenha ocorrido redução com o aumento da salinidade da água de irrigação (Figura 2). A aplicação da lâmina L1 também proporcionou aumento da MSFC e MSFT, com vantagem para F2 em relação a F1 (Tabela 1).

O principal efeito da salinidade em culturas herbáceas é o retardamento do crescimento. $\mathrm{O}$ clima é o fator que mais afeta a tolerância aos sais; muitas culturas podem tolerar grande estresse salino se as condições climáticas apresentarem baixa temperatura e alta umidade relativa do ar, opostamente a um clima quente e seco. A tolerância aos sais também depende do tipo, do método e da freqüência de irrigação. À medida que o solo seca as plantas experimentam tan- to o estresse matricial quanto o estresse osmótico, limitando a absorção de água (Rhoades et al., 2000). Como no presente trabalho o volume de água aplicado não diferiu de acordo com a salinidade da água de irrigação, a menor absorção de água pelas plantas submetidas aos tratamentos mais salinos resultou na maior umidade do solo ao longo de todo o período experimental, sendo o conteúdo de água no solo proporcional ao nível de salinidade. O potencial mátrico médio na profundidade de $0,15 \mathrm{~m}$ para os tratamentos submetidos às águas $\mathrm{S} 1$, S2 e S3 foi, respectivamente, $-10,3 ;-7,1$ e $-4,7 \mathrm{kPa}$; com isso, a redução da capacidade de absorção de água provocada pelo estresse osmótico foi, em parte, compensada pelo maior potencial mátrico.

A época em que o experimento foi desenvolvido (inverno-primavera) foi outro fator que contribuiu para a ausência de significância estatística de produção da cultura. Aproximadamente $80 \%$ do período experimental esteve compreendido durante o período de inverno, no qual a temperatura e umida- de relativa médias foram de $18,9^{\circ} \mathrm{C}$ e $74 \%$, respectivamente, registradas em uma estação meteorológica automática instalada em um posto meteorológico localizado próximo à área experimental. Utilizando as relações obtidas por Blanco \& Folegatti (1998), pode-se estimar que nesse período a temperatura e umidade no interior do ambiente protegido foram de $21^{\circ} \mathrm{C}$ e $66 \%$, respectivamente.

Além disso, a enxertia proporciona maior tolerância das culturas à salinidade, bem como aumenta a capacidade de absorção de água e nutrientes (Oda, 1995). Estes fatos associados indicam que a ausência de diferenças estatisticamente significativas para a produtividade obtida com o aumento da salinidade da água de irrigação pode estar relacionada à cultivar utilizada, às condições de clima e solo em que o experimento foi conduzido e à maior tolerância do pepino enxertado à salinidade, em relação ao pepino não enxertado, não sendo possível determinar com exatidão o grau de influência que cada um destes fatores exerceu sobre os resultados obtidos. 


\section{AGRADECIMENTOS}

À Fundação de Amparo à Pesquisa no Estado de São Paulo, pela concessão dos recursos financeiros utilizados neste trabalho.

\section{LITERATURA CITADA}

BERNARDO, S. Manual de Irrigação. 6.ed. Viçosa: Imprensa Universitária, 1995. 657 p.

BLANCO, F.F.; FOLEGATTI, M.V. Estimativa da evapotranspiração em estufa plástica utilizando dados meteorológicos externos. In: BALBUENA, R.H.; BENEZ, S.H.; JORAJURÍA, D. (Ed.) Avances en el manejo del suelo y agua en la ingeniería rural latinoamericana. La Plata: UNLP, 1998. p. 361-366.

BLANCO, F.F.; FOLEGATTI, M.V. Salinização do solo em ambiente protegido sob fertirrigação. In: WORKSHOP DE FERTIRRIGAÇÃO, 1. 1999, Piracicaba. Resumos... Piracicaba: DER/ ESALQ/USP, 1999. p. 3-4.

CAÑIZARES, K.A.L. A cultura do pepino. In: GOTO, R.; TIVELLI, S.W. (Org.) Produção de hortaliças em ambiente protegido: condições subtropicais. São Paulo: UNESP, 1998. p. 195-223.
CASTILlA, N.; ELIAS, F.; FERERES, E. Evapotranspiracion de cultivos horticolas en invernadero en Almeria. Investigacion Agraria: Produccion y Proteccion Vegetal, v. 5, n. 1, p. $117-$ 125, 1990.

CHARTZOULAKIS, K.S. Effects of saline irrigation water on germination, growth and yield of greenhouse cucumber. Acta Horticulturae, v. 287, p. 327-334, 1990.

GORNAT, B.; GOLDBERG, D.; RIMON, D.; BEN-ASHER, J. The physiological effect of water quality and method of application on tomato, cucumber, and pepper. Journal of the American Society for Horticultural Science, v. 98, n. 2, p. 202-205, 1973.

JONES, R.W.; PIKE JR., L.M.; YOURMAN, L.F. Salinity influences cucumber growth and yield. Journal of the American Society for Horticultural Science, v. 114, n. 4, p. 547-551, 1989.

MAAS, E.V.; HOFFMAN, G.J. Crop salt tolerance - current assessment. Journal of the Irrigation and Drainage Division, v. 103, n. IR2, p. 115-134, 1977.

MARTÍNEZ-RAYA, A.; CASTILLA, N. Evapotranspiracion del pimiento en invernadero en Almeria. ITEA: Produccion Vegetal, n. 85, p. 57-62, 1989.

MEDEIROS, J.F.; GHEYI, H.R. A qualidade da água de irrigação. Mossoró: ESAM, 1994. 60 p.
MEDEIROS, J.F.; PEREIRA, F.A.C.; FOLEGATTI, M.V.; PEREIRA, A.R.; VILLA NOVA, N.A. Comparação entre a evaporação em tanque Classe-A padrão e em minitanque, instalados em estufa e estação meteorológica. In: $\mathrm{CON}$ GRESSO BRASILEIRO DE AGROMETEOROLOGIA, 10, Piracicaba, 1997. Anais. Piracicaba, SBA, 1997. p. 228-230.

ODA, M. New grafting methods for fruit-bearing vegetables in Japan. Japan Agricultural Research Quarterly, v. 29, n. 3, p. 187-194, 1995.

OLIVEIRA, A.S.; SALATI, E. Um estudo sobre as águas subterrâneas da região de Piracicaba. Anais da E. S. A. "Luiz de Queiroz", v. 38, p. 885907, 1981.

PAPADOPOULOS, A.P. Growing greenhouse seedless cucumbers in soil and in soilless media. Ottawa: Agriculture and Agri-Food Canada, 1994. 126 p. (Agriculture and Agri-Food Canada Publication, 1902/E)

RHOADES, J.D.; KANDIAH, A.; MASHALI, A.M.

Uso de águas salinas para produção agrícola. Trad. de GUEYI, H.R.; SOUSA, J.R.; QUEIROZ, J.E. Campina Grande: UFPB, 2000. $117 \mathrm{p}$.

SONNEVELD, C.; VOOGT, S.J. Effects of saline irrigation water on glasshouse cucumbers. Plant and Soil, v. 49, n. 3, p. 595-606, 1978.

VAN HOORN, J.W.; VAN ALPHEN, J.G. Salinity control. In: RITZEMA, H.P. (Ed.). Drainage principles and applications. 2.ed. Wageningen: ILRI, 1994. p. 533-600. (ILRI Publication, 16) 